\title{
Variedades de feijão e seus efeitos na qualidade protéica, na glicemia e nos lipídios sangüíneos em ratos
}

\author{
Varieties of beans and their effects on protein quality, glicemy, and blood lipids in rats
}

\author{
Dagnith Liz Bejarano LUJÁN ${ }^{1}$, Alda Jusceline LEONEL ${ }^{1}$, \\ Priscila Zaczuk BASSINELLO², Neuza Maria Brunoro COSTA ${ }^{1 \star}$
}

\begin{abstract}
Resumo
O feijão representa importante fonte de proteína e pode auxiliar na modulação dos níveis de glicose e lipídios sangüíneos. Objetivou-se avaliar o valor protéico e funcional de variedades de feijão. Para a qualidade protéica foram usados 7 grupos $(n=6)$ de ratos recém desmamados: um recebeu dieta aprotéica por 14 dias e os demais, dietas contendo 9-10\% de proteína como caseína ou como um dos feijões (Ouro Branco, Pérola, BRS Radiante, Diamante Negro e Talismã). No segundo experimento, 4 grupos $(\mathrm{n}=10)$ de ratos adultos receberam dietas de caseína, Ouro Branco, Diamante Negro e Talismã por 28 dias. Ouro Branco apresentou maior Coeficiente de Eficiência Protéica (PERr = 61,18\%) do que os demais e o BRS Radiante o menor $(\mathrm{PERr}=44,60 \%)$. Quanto à Razão Protéica Líquida (NPR) e à digestibilidade, não houve diferença ( p > 0,05) entre os grupos, variando de 67,05 a 78,19\% e de 78,70 a $84,88 \%$, respectivamente. As dietas de Diamante Negro e Talismã promoveram redução da glicemia de 30 e 26\%, respectivamente, em relação à caseína, não sendo, porém, significativa; não houve diferença $(\mathrm{p}>0,05)$ entre os grupos quanto aos níveis séricos de colesterol e triacilgliceróis. Assim, de acordo com as necessidades apresentadas pelas populações, suas demandas nutricionais e funcionais podem ser supridas por diferentes feijões.
\end{abstract}

Palavras-chave: feijão; proteína; perfil lipídico; glicose; colesterol.

\begin{abstract}
Beans are important source of protein in the Brazilian staple food and may modulate the blood glucose and lipid levels. The objective of this study was to evaluate the protein quality and functional properties of varieties of beans. Seven groups $(n=6)$ of weaning rats were used for the bean protein quality analysis. The first group was fed protein-free diet for 14 days, and the remaining were fed diets with 9 to $10 \%$ protein provided by either casein or one of the 5 varieties of beans (Ouro Branco, Pérola, BRS Radiante, Diamante Negro, and Talismã). In a further study, 4 groups ( $\mathrm{n}=10)$ of adult rats were fed diets containing either casein or "Ouro Branco", "Diamante Negro", and "Talismã" beans (30 g.100 g ${ }^{-1}$ diet), for 28 days. "Ouro Branco", white beans, showed higher relative Protein Efficiency Ratio (rPER = 61.18\%) than the other varieties, and the "BRS Radiante", brown beans, showed the lowest value ( $(\mathrm{PER}=44.60 \%)$. In terms of Net Protein Ratio (NPR) and digestibility, no difference was observed between the varieties studied ( $\mathrm{p}>0.05$ ), varying from 67.05 to $78.19 \%$, and 78.70 to $84.88 \%$, respectively. "Diamante Negro", black and brown beans, and the "Talismã" beans showed 30 and $26 \%$ reduction of blood glucose, respectively, compared to the casein group but not at significant levels. No difference ( $\mathrm{p}>0.05$ ) was observed between the varieties in terms of serum cholesterol and triacylglycerol levels. This indicates that the nutritional and functional demands of the population may be supplied by different varieties of beans.

Keywords: beans; protein; lipids; glucose; cholesterol.
\end{abstract}

\section{Introdução}

$\mathrm{Na}$ América Latina as leguminosas suprem quantidades significativas de energia e proteína para grande parte da população. O consumo do feijão comum é relativamente alto, principalmente para pessoas com escassos recursos, nas quais geralmente se encontra a desnutrição em graus variáveis (WELCH et al., 2002). No Brasil o feijão é amplamente consumido, apesar do consumo per capita ter caído de $19 \mathrm{~kg} / \mathrm{hab} / \mathrm{ano}$ na década de 90 para $16 \mathrm{~kg} / \mathrm{hab} /$ ano na presente década, possivelmente pelo processo de urbanização e as mudanças nos hábitos alimentares (CONAB, 2006; WANDER, 2007).

As proteínas do feijão apresentam, entretanto, baixos teores e biodisponibilidade reduzida de aminoácidos sulfurados (PEREIRA; COSTA, 2002). A qualidade protéica é ainda influen- ciada pela presença de fatores antinutricionais, que se encontram presentes em diferentes teores de acordo com a variedade do feijão (GENOVESE; LAJOLO, 2001). Contudo, efeitos também são atribuídos para alguns destes compostos no tratamento de enfermidades como diabetes, doenças cardiovasculares e câncer do cólon (MANISHA et al., 2003; WOO et al., 2003). Ainda, determinados constituintes do feijão, como fibras, taninos, fitatos e inibidores de amilase, correlacionam-se inversamente com a digestão de carboidratos e resposta glicêmica (ANDERSON; SMITH; WASNOCK, 1999).

É preocupante o aumento de diabetes em todo o mundo, considerando que de cada 20 mortes, uma é atribuída a essa doença. Segundo previsões da Organização Mundial de Saúde,

Recebido para publicação em 11/5/2007

Aceito para publicação em 29/8/2007 (002523)

1 Departamento de Nutrição e Saúde, Universidade Federal de Viçosa - UFV, CEP 36570-000, Viçosa - MG, Brasil, E-mail: nmbc@ufv.br

${ }^{2}$ Empresa Brasileira de Pesquisa Agropecuária - EMBRAPA, Centro Nacional de Arroz e Feijão, Rodovia Goiânia km 12, CEP 75375-000, Santo Antônio de Goiás - GO, Brasil

${ }^{*}$ A quem a correspondência deve ser enviada 
nos próximos 25 anos o número de diabéticos pode dobrar em todo o mundo, chegando a 370 milhões de pacientes. $\mathrm{O}$ número de diabéticos no Brasil pode chegar a 11,3 milhões até 2030 (WHO, 2003).

A alta prevalência de doenças crônicas não transmissíveis tem levado à busca de alimentos funcionais, visando uma alimentação saudável. Essa demanda do consumidor requer o conhecimento das propriedades nutricionais e funcionais de alimentos que fazem parte do seu hábito alimentar, como o feijão. Essas informações contribuirão com os programas de melhoramento genético na obtenção de linhagens com melhores características nutricionais e funcionais que atendam às necessidades de diferentes grupos da população.

O objetivo deste estudo foi avaliar a qualidade protéica de cinco cultivares de feijão e o efeito de três destas cultivares na glicemia e no perfil lipídico em ratos.

\section{Material e métodos}

\subsection{Experimento I: avaliação da qualidade protéica}

Foram utilizados 42 ratos machos Wistar, recém desmamados, oriundos do Biotério Central do Centro de Ciências Biológicas e da Saúde, da Universidade Federal de Viçosa, com peso médio inicial de $57,7 \mathrm{~g}$, distribuídos aleatoriamente em sete grupos de seis animais. Os animais foram mantidos em gaiolas individuais em ambiente com fotoperíodo de 12 horas e temperatura média de $26^{\circ} \mathrm{C}$.

Utilizaram-se cinco variedades de feijões (Phaseolus vulgaris L.), correspondentes aos grupos branco (Ouro Branco), preto (Diamante Negro) e marrom-rajado (BRS Radiante, Pérola e Talismã). As variedades Ouro Branco, Pérola, BRS Radiante e Diamante Negro, fornecidas pela Empresa Brasileira de Pesquisa Agropecuária (EMBRAPA), Goiânia-GO, e a variedade Talismã, fornecida pela Universidade Federal de Viçosa foram recém colhidas e armazenadas em freezer por 2 meses até o início do experimento.

Os grãos foram submetidos à cocção em água (1: 1,5 p/v), em panela de pressão durante 30 minutos. O feijão cozido foi seco em estufa com circulação de ar a $65^{\circ} \mathrm{C}$, por 10 horas, e em seguida moído em multiprocessador doméstico.

O teor de proteína da farinha de feijão foi determinado pelo método de semimicro Kjeldahl (AOAC, 1998), multiplicando-se o teor de nitrogênio pelo fator 6,25.

O desenho experimental foi constituído de 6 tratamentos testes, utilizando-se dietas semipurificadas, com base na dieta AIN-93G (REEVES; NIELSEN; FAHEY, 1993). O teor de proteína foi reduzido para valores entre 9 e $10 \%$, a fim de avaliar a qualidade das fontes protéicas. A celulose foi suprimida das dietas que continham as variedades de feijão, pois de acordo com Cruz (2000), a quantidade de fibras presentes nos feijões já seria suficiente para cobrir as necessidades dos animais. Os animais receberam água destilada e suas dietas ad libitum por 14 dias. A composição das dietas encontra-se na Tabela 1.

O consumo alimentar e o peso corporal dos animais foram registrados semanalmente. Para a determinação da digestibilidade, as dietas foram marcadas com carmin $\left(100 \mathrm{mg} .100 \mathrm{~g}^{-1}\right)$ e as fezes foram coletadas por um período de 4 dias. $O$ teor protéico das dietas e do nitrogênio fecal foi determinado pelo método semimicro Kjeldahl. A avaliação da qualidade protéica foi determinada pelo Coeficiente de Eficiência Protéica (PER) (AOAC, 1975), Razão Protéica Líquida (NPR) (BENDER; DOELL, 1957) e digestibilidade verdadeira (DV) (AMAYA, 1991).

\subsection{Experimento II: efeitos na glicemia e lipídios sangüíneos}

Foram utilizados 40 ratos machos Wistar adultos, oriundos do Biotério Central do Centro de Ciências Biológicas e da Saúde, da Universidade Federal de Viçosa, com peso corporal variando

Tabela 1. Composição das dietas experimentais (Experimento 1).

\begin{tabular}{|c|c|c|c|c|c|c|c|}
\hline \multirow[t]{2}{*}{ Ingredientes $\left(\mathrm{g} .100 \mathrm{~g}^{-1}\right)$} & \multicolumn{7}{|c|}{ Dietas $^{\mathrm{a}}$} \\
\hline & $\mathrm{LN}$ & CAS & D1 & $\mathrm{D} 2$ & D3 & $\mathrm{D} 4$ & D5 \\
\hline Caseína & - & 11,56 & - & - & - & - & - \\
\hline Feijão Ouro Branco ${ }^{1}$ & - & - & 43,88 & - & - & - & - \\
\hline Feijão Pérola ${ }^{1}$ & - & - & & 43,56 & - & - & - \\
\hline Feijão BRS Radiante $^{1}$ & - & - & - & - & 46,27 & - & - \\
\hline Feijão Diamante Negro ${ }^{1}$ & - & - & - & - & - & 43,66 & - \\
\hline Feijão Talismã ${ }^{1}$ & - & - & - & - & - & - & 44,37 \\
\hline Maltodextrina $^{2}$ & 13,2 & 13,2 & 13,2 & 13,2 & 13,2 & 13,2 & 13,2 \\
\hline Celulose microfina ${ }^{3}$ & 5,0 & 5,0 & - & - & - & - & - \\
\hline Sacarose $^{4}$ & 10,0 & 10,0 & 10,0 & 10,0 & 10,0 & 10,0 & 10,0 \\
\hline Óleo de soja ${ }^{4}$ & 7,0 & 7,0 & 7,0 & 7,0 & 7,0 & 7,0 & 7,0 \\
\hline Mistura salínica $^{5 \star}$ & 3,5 & 3,5 & 3,5 & 3,5 & 3,5 & 3,5 & 3,5 \\
\hline Mistura vitamínica $^{3 *}$ & 1,0 & 1,0 & 1,0 & 1,0 & 1,0 & 1,0 & 1,0 \\
\hline L-cistina ${ }^{3}$ & 0,3 & 0,3 & 0,3 & 0,3 & 0,3 & 0,3 & 0,3 \\
\hline Bitartarato de colina ${ }^{3}$ & 0,25 & 0,25 & 0,25 & 0,25 & 0,25 & 0,25 & 0,25 \\
\hline Amido de milho (q.s.p. $)^{4}$ & 59,75 & 48,19 & 20,87 & 19,39 & 18,48 & 21,09 & 20,38 \\
\hline Proteína (\%) & - & 9,93 & 9,23 & 9,35 & 9,0 & 9,37 & 10,29 \\
\hline
\end{tabular}

${ }^{1}$ Farinha obtida a partir das amostras de feijão analisadas; ${ }^{2}$ Tangará - Importadora e Exportadora Ltda.; ${ }^{3}$ Rhoster Indústria e Comércio Ltda.; ${ }^{4}$ Obtido no comércio de Viçosa, MG;

${ }^{5}$ Elaborada no laboratório do Departamento de Nutrição e Saúde - UFV; e ${ }^{\star}$ Segundo Reeves et al. (1993). 
de 190 a 200 g. Nesse experimento não foram usados os mesmos animais da primeira etapa, pois aqui eram necessários ratos adultos, enquanto lá foram usados ratos recém-desmamados, além da diferença de duração entre os dois experimentos. Os animais foram divididos aleatoriamente em quatro grupos de dez animais e mantidos em gaiolas individuais, em ambiente com fotoperíodo de 12 horas e temperatura média de $26^{\circ} \mathrm{C}$, com acesso livre à água e uma dieta comercial por 7 dias antes do início do experimento.

Foi analisada neste estudo uma variedade de feijão de cada grupo de cor, dos grupos: Ouro Branco (branco), Diamante Negro (preto) e Talismã (marrom-rajado), armazenados em freezer por 4 meses até o início do experimento. A escolha dessas variedades deu-se pela melhor qualidade protéica apresentada pelo feijão branco; de acordo com a literatura vista (PEREIRA; COSTA, 2002; AMAYA; ACEVEDO; BRESSANI, 1991); o feijão preto por apresentar alta quantidade de fatores antinutricionais e, dentro das variedades marrom-rajado, o Talismã foi escolhido por ser um feijão novo no mercado, que necessita de estudos para determinação de suas qualidades nutricionais. Os grãos foram submetidos à cocção em água, na proporção de 1:2 (p/v), em panela de pressão durante 40 minutos. $\mathrm{O}$ feijão cozido foi seco em estufa com circulação de ar a $65^{\circ} \mathrm{C}$, por 12 horas, e em seguida, moído em multiprocessador doméstico.

Após o preparo, determinaram-se os teores de proteína, lipídios, umidade e cinzas, de acordo com metodologia da AOAC (AOAC, 1998); o teor de carboidrato foi determinado por diferença.

O desenho experimental foi constituído de 4 tratamentos teste, utilizando-se dietas semipurificadas, com base no fornecimento da quantidade de proteína necessária de acordo com AIN-93M (REEVES; NIELSEN; FAHEY, 1993). As dietas continham $14 \%$, tanto para o grupo padrão alimentado com a dieta a base de caseína, como para os outros grupos tratados que receberam dieta semelhante à padrão, adicionada, em base seca, por 30\% de cada variedade de feijão. A caseína foi utilizada em todas as dietas para que se conseguisse fornecer a quantidade de proteína necessária preconizada pela AIN-93M.

Após período de adaptação, os animais foram alimentados com dieta à base de caseína (grupo padrão) ou com dieta semelhante à padrão, adicionada, em base seca, por $30 \%$ de cada variedade de feijão. Os animais receberam água destilada e as respectivas dietas ad libitum por 28 dias. A composição das dietas está mostrada na Tabela 2.

O consumo alimentar, a ingestão hídrica e o peso corporal dos animais foram registrados semanalmente.

Nas manhãs dos dias $1^{\circ}, 7^{\circ}, 14^{\circ}, 21^{\circ}$ e $28^{\circ}$ do experimento, os níveis de glicose foram monitorados por leitura em glicosimetro (Accu-Chek Advantage) utilizando sangue obtido da parte distal da cauda dos ratos, expressando os valores da glicemia em miligramas por decilitro $\left(\mathrm{mg} \cdot \mathrm{dL}^{-1}\right)$.

No final do experimento, após jejum noturno de 12 horas, os animais foram anestesiados $\operatorname{com} \mathrm{CO}_{2}$ e, após aberturas torácica e abdominal, amostras sangüíneas foram coletadas por secção da aorta abdominal em duas alíquotas de aproximadamente $3 \mathrm{~mL}$
Tabela 2. Composição das dietas experimentais (Experimento 2).

\begin{tabular}{lcccc}
\hline \multirow{2}{*}{${\text { Ingredientes }\left(\mathrm{g} .100 \mathrm{~g}^{-1} \text { ) }\right.}$} & \multicolumn{4}{c}{ Dietas $^{\mathrm{a}}$} \\
\cline { 2 - 5 } & $\mathrm{CAS}$ & $\mathrm{B}$ & $\mathrm{P}$ & $\mathrm{T}$ \\
\hline Caseína & 14,0 & 9,14 & 9,09 & 9,22 \\
Feijão Ouro Branco $^{1}$ & - & 30,0 & - & - \\
Feijão Diamante Negro $^{1}$ & - & - & 30,0 & - \\
Feijão Talismã $^{1}$ & - & - & - & 30,0 \\
Maltodextrina $^{2}$ & 15,5 & 15,5 & 15,5 & 15,5 \\
Sacarose $^{4}$ & 10,0 & 10,0 & 10,0 & 10,0 \\
Óleo de soja $^{4}$ & 4,0 & 4,0 & 4,0 & 4,0 \\
Celulose microfina $^{3}$ & 5,0 & - & - & - \\
Mistura salínica $^{5 *}$ & 3,5 & 3,5 & 3,5 & 3,5 \\
Mistura vitamínica $^{3 *}$ & 1,0 & 1,0 & 1,0 & 1,0 \\
L-cistina $^{3}$ & 0,18 & 0,18 & 0,18 & 0,18 \\
Bitartarato de colina $^{3}$ & 0,25 & 0,25 & 0,25 & 0,25 \\
Amido de milho (q.s.p. $^{4}$ & 46,57 & 26,43 & 26,48 & 26,35
\end{tabular}

${ }^{\mathrm{a} C A S:}$ caseína; B: feijão Ouro Branco; P: feijão Diamante Negro; T: feijão Talismã; ${ }^{1}$ Farinha obtida a partir das amostras de feijão analisadas; ${ }^{2}$ Tangará - Importadora e Exportadora Ltda.; ${ }^{3}$ Rhoster Indústria e Comércio Ltda.; ${ }^{4}$ Obtido no comércio de Viçosa, MG; ${ }^{5}$ Elaborada no laboratório do Departamento de Nutrição e Saúde - UFV; e Segundo Reeves et al. (1993).

cada. Uma alíquota foi acondicionada em tubo com anticoagulante para determinação de hemoglobina glicosilada. A outra foi centrifugada a $2368 \times$ g, por 15 minutos, para a obtenção do plasma, que foi armazenado a $-18^{\circ} \mathrm{C}$ para posterior análise das concentrações plasmáticas de glicose, colesterol total e triacilgliceróis.

O nível de colesterol total foi determinado pelo método de Allain et al. (1974), utilizando o kit da bioMérieux e o de triacilglicerol pela metodologia de Bucolo e David (1973), utilizando o kit Bioclin. Para análise de glicose foi utilizado o kit Doles Reagentes, de acordo com Trinder (1969). Para a dosagem de hemoglobina glicosilada $\left(\mathrm{HbA}_{1}\right)$, utilizou-se o kit Doles tomando-se uma amostra do sangue total (contendo heparina), que foi misturado com a solução hemolisante e em seguida transferida uma parte do hemolisado para o tubo com resina catiônica. A hemoglobina não glicosilada ligou-se à resina, ficando a $\mathrm{HbA}_{1}$ no sobrenadante. A percentagem $\mathrm{HbA}_{1}$ em relação à hemoglobina total foi calculada por absorbância a $415 \mathrm{~nm}$.

Os experimentos animais foram conduzidos seguindo os Princípios Éticos na Experimentação Animal, preconizados pelo Colégio Brasileiro de Experimentação Animal (COBEA) (2003).

Os dados obtidos foram submetidos à Análise de Variância (ANOVA) e teste de Tukey a 5\% de significância, com o auxílio do programa SAEG-UFV.

\section{Resultados e discussão}

Os ratos alimentados com as dietas de feijão, no Experimento 1, apresentaram menor ganho de peso $(\mathrm{p}<0,05)$ do que o grupo com dieta de caseína. Dentre as variedades estudadas, o feijão Ouro Branco promoveu maior ganho de peso (35\% em relação ao ganho de peso do grupo alimentado com 
caseína) e o BRS Radiante o menor (18\% em relação ao ganho de peso do grupo alimentado com caseína).

Os resultados obtidos de PER e PER (\%), NPR e NPR (\%) e digestibilidade são apresentados na Tabela 3.

A variedade BRS Radiante apresentou valores de PER e PER (\%) inferiores aos da variedade Ouro Branco $(p<0,05)$. Todas as variedades de feijão estudadas apresentaram PER, NPR e Digestibilidade inferiores $(\mathrm{p}<0,05)$ à caseína. Os dados de NPR e NPR (\%) foram mais semelhantes entre as dietas à base de feijão e superiores ao seu respectivo PER.

No Experimento 2, não foram observadas diferenças significativas em relação ao ganho de peso (GP), dados esses que variaram de $107 \%$ em relação ao ganho de peso do grupo alimentado com caseína (Diamante Negro) a 96\% de GP em relação ao mesmo grupo (Talismã).

Constatou-se que as dietas de feijão promoveram ganho de peso equivalente ao grupo de caseína, pelo fato dos ratos serem adultos e alimentados com uma dieta de maior teor de proteína do que no experimento I, superando as deficiências de aminoácidos indispensáveis e a baixa digestibilidade do feijão.

Nas determinações de glicose sangüínea por fita, não houve diferença estatística entre as variedades de feijão e destas com relação à caseína (Figura 1).

Foi observado que as dietas dos feijões Diamante Negro e Talismã promoveram redução de glicose de 30 e 26\%, respectivamente, em relação à caseína (Tabela 4), possivelmente pela maior concentração de taninos existentes nesses feijões, porém essa diferença não foi significativa.

Os valores obtidos para $\mathrm{HbA}_{1}$ situaram-se na faixa dos valores de referência para não diabéticos ou diabéticos bem controlados, no intervalo de 4,5 a 8\% (DOLES, 2003).
Não houve diferença significativa quanto aos níveis de colesterol sérico e triacilgliceróis entre as variedades de feijão (Tabela 4). No entanto, foi observado que as dietas de feijão Talismã, Diamante Negro e Ouro Branco reduziram em 13, 9 e $7 \%$, respectivamente, o colesterol sérico em relação à caseína, diferença essa que também não se apresentou significativa.

Estudos realizados por Bressani e Elias (1984), Cruz (2000) e Cruz (2005), assim como os realizados no presente estudo, demonstraram melhor qualidade protéica do feijão branco quando comparado com o vermelho, preto ou marrom.

Entre as variedades analisadas, Pérola e Diamante Negro apresentaram maiores valores de NPR, enquanto BRS Radiante e Talismã obtiveram os menores valores de NPR. A variação

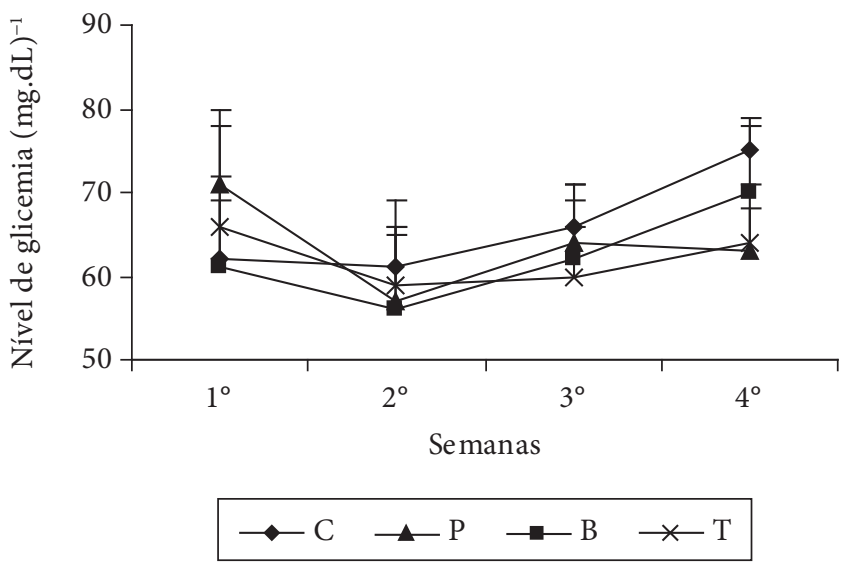

Figura 1. Glicemia dos ratos, durante as quatro semanas que receberam as dietas de caseína e feijões $(\mathrm{p}<0,05)$. Valores obtidos por punção sangüínea da cauda dos animais.

Tabela 3. Médias \pm desvio padrão de PER, PER (\%), NPR, NPR (\%) e digestibilidade dos diferentes tratamentos com dietas à base de feijão e caseína.

\begin{tabular}{lccccc}
\hline \multicolumn{1}{c}{ Dieta } & PER $^{*}$ & PER $^{*}(\%)$ & NPR $^{*}$ & NPR $^{*}(\%)$ & DG $^{*}$ \\
\hline Caseína & $3,81 \pm 0,45^{\mathrm{a}}$ & $100^{\mathrm{a}}$ & $4,37 \pm 0,43^{\mathrm{a}}$ & $10^{\mathrm{a}}$ & $94,60 \pm 2,20^{\mathrm{a}}$ \\
Ouro Branco & $2,34 \pm 0,14^{\mathrm{b}}$ & $61,18 \pm 3,60^{\mathrm{b}}$ & $3,32 \pm 0,21^{\mathrm{b}}$ & $75,83 \pm 4,72^{\mathrm{bc}}$ & $84,88 \pm 1,64^{\mathrm{b}}$ \\
Pérola & $2,12 \pm 0,26^{\mathrm{bc}}$ & $55,35 \pm 6,68^{\mathrm{bc}}$ & $3,36 \pm 0,25^{\mathrm{b}}$ & $76,60 \pm 5,74^{\mathrm{b}}$ & $78,70 \pm 2,43^{\mathrm{b}}$ \\
BRS Radiante & $1,72 \pm 0,30^{\mathrm{c}}$ & $44,60 \pm 7,82^{\mathrm{d}}$ & $3,09 \pm 0,28^{\mathrm{b}}$ & $70,70 \pm 6,37^{\mathrm{bc}}$ & $80,62 \pm 2,64^{\mathrm{b}}$ \\
Diamante Negro & $2,14 \pm 0,24^{\mathrm{bc}}$ & $56,00 \pm 6,36^{\mathrm{bc}}$ & $3,42 \pm 0,32^{\mathrm{b}}$ & $78,19 \pm 7,38^{\mathrm{b}}$ & $81,90 \pm 5,77^{\mathrm{b}}$ \\
Talismã & $1,91 \pm 0,28^{\mathrm{bc}}$ & $49,86 \pm 7,38^{\mathrm{cd}}$ & $2,94 \pm 0,13^{\mathrm{b}}$ & $67,05 \pm 2,95^{\mathrm{c}}$ & $79,84 \pm 4,98^{\mathrm{b}}$ \\
\hline
\end{tabular}

${ }^{*}$ As médias dentro da mesma coluna, seguidas da mesma letra, não diferem entre si, pelo teste de Tukey $(\mathrm{p}<0,05)$.

Tabela 4. Concentrações de glicose, hemoglobina glicosilada, colesterol e triacilglicerol de ratos alimentados com dietas experimentais por 28 dias.

\begin{tabular}{lllll}
\hline \multicolumn{1}{c}{ Dietas } & GLIC $^{*}\left(\mathrm{mg}^{\circ} \mathrm{dL}^{-1}\right)$ & $\mathrm{HbAl}^{*}(\%)$ & Colesterol total $^{*}$ & Triacilgliceróis $^{*}$ \\
\hline Caseína & $335,93 \pm 86,59$ & $4,17 \pm 0,50$ & $100,38 \pm 12,83$ & $249,21 \pm 18,75$ \\
Ouro Branco & $288,28 \pm 63,06$ & $4,73 \pm 0,43$ & $90,96 \pm 14,74$ & $232,99 \pm 48,11$ \\
Diamante Negro & $232,69 \pm 52,80$ & $4,51 \pm 0,35$ & $92,581 \pm 12,43$ & $233,47 \pm 42,84$ \\
Talismã & $247,22 \pm 77,69$ & $4,66 \pm 0,90$ & $88,68 \pm 11,35$ & $240,47 \pm 39,64$ \\
\hline
\end{tabular}

${ }^{\star}$ As médias dentro da mesma coluna, seguidas da mesma letra, não diferem entre si, pelo teste de Tukey $(\mathrm{p}<0,05)$. 
dos resultados pode ser dependente não apenas da expressão genética entre as cultivares estudadas, mas também da diferença da localização geográfica e das condições de plantio, da qualidade das proteínas das diferentes variedades, ou da diminuição de fatores antinutricionais, total ou parcialmente eliminados durante o tratamento térmico.

Sabarense et al. (1995) relataram o NPR de uma variedade vermelha recém-colhida de 1,96. Wu et al. (1996) encontraram valores de NPR e NPR (\%) para uma variedade vermelha, que variaram de 0,86 a $1,32 \%$ e de 28,8 a $41,2 \%$, respectivamente. Os valores encontrados por estes autores diferiram dos valores encontrados para a variedade BRS Radiante, que foram de 3,08 e $70,70 \%$. A variabilidade destes resultados e dos obtidos neste experimento pode ter sido influenciada tanto pela natureza química como pelo processamento e condições de armazenamento do feijão (BILBAO et al., 2000; CHIMMAD et al., 2005).

Hughes et al. (1996) determinaram a digestibilidade verdadeira das variedades Pérola e Carioca, e encontraram valores de 91,12 e $88,05 \%$, respectivamente, diferindo dos valores encontrados neste experimento, que foram de 78,70\% para Pérola e $80,62 \%$ para BRS Radiante. A variedade Talismã apresentou um valor de digestibilidade verdadeira de $79,84 \%$, semelhante aos dados encontrados para as variedades Pérola, Diamante Negro e BRS Radiante. Comparando os resultados obtidos pelas diferentes variedades, verifica-se que não diferiram estatisticamente, porém, em valores absolutos o feijão branco apresentou maior digestibilidade, seguido do feijão preto.

A melhoria da capacidade de digestão não implica necessariamente no aumento da qualidade protéica, pois os aminoácidos podem estar sendo bem absorvidos, e não participando da síntese protéica em virtude da deficiência de alguns aminoácidos essenciais. Confirmando esta afirmação, a variedade de feijão BRS Radiante, apesar de apresentar uma digestibilidade semelhante às outras variedades, apresentou o menor valor de PER e diferença estatisticamente significativa quando comparada com a variedade Ouro Branco.

Outras pesquisas mostraram que a digestibilidade de feijões de tegumento colorido é menor que tegumento não colorido, e que o feijão preto tem digestibilidade mais baixa devido ao alto conteúdo de taninos, que podem estar contribuindo para a sua baixa digestibilidade (CRUZ, 2000; 2005). Contrariamente a estes resultados, o nosso resultado com feijão preto não somente apresentou uma digestibilidade próxima ao feijão branco como também não diferiu das outras variedades. Podendo isso ser resultante de baixas concentrações de componentes antinutricionais existentes no grão estudado, após cocção.

Ramírez-Cárdenas, Leonel e Costa (2008) encontraram teores de taninos para o feijão cru que variaram de 182,60 do BRS Radiante a 33,38 do Ouro Branco expressos em mg de catequina/100 g de feijão. Após tratamento térmico, estes teores foram reduzidos em 66\% para as variedades Ouro Branco e Diamante Negro, porém para as outras variedades houve uma redução de $80 \%$. Estes achados confirmam os baixos valores dos parâmetros de avaliação da qualidade protéica e o fato das variedades vermelho (BRS Radiante), preto (Diamante Negro) e carioca (Pérola, Talismã) terem apresentado menor digestibi- lidade. Além disso, foi observado que o feijão preto, apesar de apresentar um teor de tanino maior quando comparado com o feijão branco, apresentou digestibilidade verdadeira semelhante, confirmando o fato de que o tratamento com calor não só reduz o teor de taninos, mas também melhora a digestibilidade das proteínas do feijão.

Outros componentes responsáveis pelo baixo valor nutritivo do feijão são usualmente atribuídos à presença de fatores tóxicos não estáveis ao calor, incluindo inibidores de tripsina e hemaglutininas. Relatam-se baixos valores na concentração dos inibidores de tripsina para as variedades em estudo, variando de 0,016 do feijão Ouro Branco a 0,362 do feijão Pérola em mg tripsina/g de amostra, sugerindo que o aquecimento foi eficaz na inativação de grande parte dos inibidores de tripsina (CRUZ, 2000). Rayas-Duarte et al. (1992), ao analisarem nove variedades de feijão comum (P. vulgaris $L$.), encontraram uma variação de 3,40 a 9,24 mg de tripsina inibida/g de amostra para o feijão cozido em água fervente por 30 minutos.

Pesquisas com diversas cultivares demonstraram que o feijão comum varia amplamente quanto à presença de inibidores de tripsina termoestáveis, e que as ligações dissulfídricas e a cisteína contribuem para a estabilização da estrutura terciária da proteína e, portanto, há maior temoestabilidade desses inibidores (RAYAS-DUARTE; BERGERON; NIELSEN, 1992).

É possível que os inibidores de protease não tenham apresentado atividade fisiológica significativa nas diferentes variedades de feijão estudadas, não afetando significativamente a digestibilidade protéica do feijão cozido. Acredita-se que a temperatura e o tempo de cocção influenciaram estes resultados, otimizando a redução dos fatores antinutricionais.

Tem-se relatado que a fibra é outro interferente na digestibilidade protéica do feijão. Cruz (2000) determinou a Fibra Alimentar Total (FAT), a Fibra Alimentar Insolúvel (FAI) e a Fibra Alimentar Solúvel (FAS) para as variedades em estudo, variando de 32,62 a 38,21 para FAT, 28,92 a 34,65 para FAI e 3,70 a 6,10 para FAS. As variedades Pérola e Carioca apresentaram os maiores teores de FAI (34,65\%) e FAS (6,10\%), respectivamente. Além disso, estes dados foram mais altos que os dados obtidos por outros autores, que trabalharam com o mesmo método enzimático gravimétrico.

A fibra alimentar pode formar complexos no conteúdo intestinal e impedir o acesso de enzimas digestivas, reduzindo a digestibilidade de amido e proteínas (LOPEZ et al., 1997). No entanto, de acordo com Cruz (2000), que estudou as mesmas variedades analisadas nesse estudo, nenhuma correlação significativa foi observada entre a digestibilidade verdadeira e as características de atividade inibitória de tripsina e fibra alimentar total, insolúvel e solúvel.

A reduzida digestibilidade protéica do feijão no presente estudo pode ser atribuída à presença de taninos e também de outros fatores antinutricionais encontrados no feijão, tais como: fitatos, fibras e inibidores de proteases, que também influenciam o valor nutritivo desta leguminosa; além disso, o feijão é deficiente em aminoácidos sulfurados, os quais são indispensáveis na síntese de proteínas (OLIVEIRA et al., 2003). 
Os fatores antinutricionais presentes nas leguminosas são geralmente destruídos parcialmente durante a cocção. Contudo, os feijões coloridos contêm pigmentos estáveis ao calor, os quais podem ser responsáveis pela baixa digestibilidade do grão. Há ampla evidência experimental no efeito dos taninos sobre a utilização da proteína, porém pouca atenção na sua influência na assimilação de dissacarídeos e amido.

Estudos in vitro mostraram que $\alpha$-amilase, maltase, sacarase e lactase foram fortemente inibidos por taninos condensados isolados de feijão preto, acrescentando que estes pigmentos também afetaram a captação de glicose, embora a absorção de glicose tenha sido menos suscetível aos taninos que à hidrólise de amido ou dissacarídeos. Sugerem ainda, que os taninos podem aumentar a proporção de amido resistente alcançando o intestino grosso (GILANI et al., 2002).

Os taninos do feijão têm sido relatados por inibir fortemente as atividades de $\alpha$-amilase, tripsina e quimiotripsina pancreáticas (CARMONA et al., 1996), mas acredita-se que além dos taninos outros componentes do feijão possam estar influenciando esses resultados.

Quando o feijão navy foi fracionado para amido, proteína, fibra e frações do soro solúveis e a digestibilidade do amido foi determinada sozinha ou em mistura com um destes compostos, observou-se uma maior redução da taxa de digestão do amido na mistura de amido com a fração de soro solúvel, sendo que a fração de soro solúvel é rica em antinutrientes, tais como: taninos, lectinas e fitatos (THOMPSON, 1988). A resposta glicêmica aumentou com a remoção de ácido fítico do feijão Navy e diminuiu com a sua adição. O mesmo fato foi observado na adição de ácido fítico na farinha de trigo em preparações de pão (THOMPON, 1993).

Todas estas pesquisas sugerem que o ácido fítico, as lectinas, os taninos ou inibidores de amilase podem reduzir a resposta glicêmica por influenciar na taxa de digestão do amido. Contudo, a resposta de glicose para um alimento teste com $50 \mathrm{~g}$ de glicose foi significativamente reduzida quando $0,8 \%$ de ácido fítico estava presente, sugerindo que o ácido fítico também pode exercer seu efeito por outros mecanismos que não envolvam a digestão do amido (DEMJEN; THOMPSON, 1991).

O efeito hipocolesterolemiante do feijão tem sido relatado e, embora os mecanismos de ação não sejam completamente entendidos, Rosa et al. (1998) apontam os possíveis efeitos das fibras solúveis, saponinas, proteína e taninos.

A importância da proteína alimentar na regulação do metabolismo do colesterol tem sido ressaltada em humanos e ratos (HUANG et al., 1993). Muitos autores têm investigado a contribuição da proteína vegetal proveniente da soja, bem como de outras leguminosas, na redução dos níveis de colesterol sangüíneo (KERN et al., 2002; GILANI et al., 2002).

Pelos resultados obtidos para as dietas de feijão e caseína, acredita-se que o feijão teve efeito hipocolesterolemiante e que, além da proteína, outros componentes do feijão podem estar participando nessa ação. Sendo apontada a presença ou ausência de componentes não protéicos (tais como fibra, ácido fítico, minerais, isoflavonas, taninos), assim como sua natureza e nível de ingestão.

De maneira geral, sugere-se que a fibra alimentar apresenta uma pequena contribuição para redução de colesterol. Acrescenta-se que a maioria dos estudos relata efeitos em tempos curtos, 3 meses ou menos. Porém, poucos estudos apresentam informações do efeito da fibra sobre os lipídios séricos em tempos longos (BIRKETVEDT et al., 2002).

Os feijões estão entre os poucos alimentos que contêm quantidades significativas, tanto de fibra alimentar solúvel quanto de insolúvel. A fibra solúvel, sendo a principal responsável pela diminuição na absorção de colesterol, atua através de vários mecanismos, inclusive interferindo com a formação de micelas e com as interações entre enzimas e substratos, além da sua capacidade de retenção de água (HUGHES, 1991).

\section{Conclusões}

Baseando-se nos parâmetros de PER, NPR e digestibilidade, a variedade Ouro Branco ressaltou-se com um melhor desempenho nutricional e a variedade BRS Radiante obteve menor valor, diferindo das outras variedades analisadas.

Acredita-se que entre os fatores antinutricionais presentes no feijão, os taninos contribuíram com a redução da digestibilidade e qualidade protéica. No entanto, é de se esperar que outros fatores inerentes ao feijão interfiram nestes parâmetros, assim como o tipo de processo ao qual o feijão é submetido.

As dietas de feijão promoveram redução dos níveis de glicose, colesterol e triacilgliceróis plasmáticos em relação à caseína. Apesar dessa diferença não ter sido significativa, talvez por causa do tamanho da amostra, acredita-se que os taninos influenciaram nestes resultados. Por isso, a presença deste composto, assim como de outros antinutrientes, deve ser cuidadosamente avaliada.

Acredita-se que as diferenças expressas nas variedades do feijão tenham sido influenciadas pela cor do grão devido à localização dos taninos na casca, assim como a presença de outros fatores antinutricionais presentes no grão.

O feijão branco apresentou melhor qualidade protéica e os feijões de cor o melhor potencial para controle da glicemia e dos lipídios sanguíneos, indicando que a recomendação de consumo de uma determinada variedade de feijão pode ser direcionada às demandas nutricionais ou funcionais da população alvo.

\section{Agradecimentos}

Os autores agradecem à EMBRAPA Arroz e Feijão pelo apoio financeiro e ao professor Sérgio Luís Pinto da Matta pela participação no ensaio clínico.

O presente artigo é baseado na dissertação de mestrado para obtenção do título de Magister Scientiae como parte das exigências do Curso de Mestrado em Ciência da Nutrição da Universidade Federal de Viçosa. Ano de defesa: fevereiro 2004. 120 pag. 
Titulo: "Variedades de feijão e seus efeitos na qualidade protéica, na glicemia e nos lipídios sanguíneos em ratos."

\section{Referências bibliográficas}

AOAC - Association Of Official methods Analytical Chemists. Official Methods of Analysis of the Association Chemistry. $16^{\text {th }}$ ed. Washington, D.C., 1998.

. Official Methods of Analysis of the Association Chemistry. $12^{\text {th }}$ ed. Washington, D.C., 1975.

ALLAIN, C. C. et al. Enzymatic determination of total cholesterol. Clinical Chemistry, v. 20, n. 4, p. 470-475, 1974.

AMAYA, H.; ACEVEDO, E.; BRESSANI, R. Efecto del recalentamiento sobre la disponibilidad de hierro y valor nutritivo de la proteína del frijol negro (Phaseolus vulgaris) cocido. Archivos Latinoamericanos de Nutrición, v. 16, n. 2, p. 222-237, 1991.

ANDERSON, J. W.; SMITH, B. M.; WASNOCK, C. S. Cardiovascular and renal benefits of dry bean and soybean intake. The American Journal of Clinical Nutrition, v. 70, suppl., p. 464S-474S, 1999.

BENDER, A. E.; DOELL, B. H. Biological evaluation of proteins: a new aspect. British Journal of Nutrition, v. 11, n. 2, p. 140-148, 1957.

BILBAO, T. et al. Changes in the protein quality of red beans (Phaseolus vulgaris L.) and peas (Pisum sativum L.). Effects of storage and domestic processing. Alimentaria, v. 37, n. 314, p. 151-156, 2000.

BIRKETVEDT, G. S. et al. Dietary supplementation with bean extract improves lipid profile in overweight and obese subjects. Nutrition, v. 18, n. 9, p. 729-733, 2002.

BRESSANI, R.; ELIAS, L. G. Relación entre la digestibilidad y el valor proteínico del frijol comum (Phaseolus vulgaris). Archivos Latinoamericanos de Nutrición, v. 34, n. 1, p. 189-197, 1984.

BUCOLO, G.; DAVID, H. Quantitative determination of serum triglycerides by the use of enzymes. Clinical Chemistry, v. 19, n. 5, p. 476-482, 1973.

CARMONA, A. et al. Effect of black bean tannins on in vitro carbohydrate digestion and absorption. Journal of Nutritional Biochemistry, v. 7, n. 8, p. 445-450, 1996.

CHIMMAD, B. V. et al. Nutritional quality of black bean (Phaseolus) seeds. Journal of Food Science and Technology, v. 42, n. 1, p. 53-55, 2005.

COBEA - Colégio Brasileiro de Experimentação Animal. 2003. Princípios éticos na experimentação animal. Disponível em: <http://www.cobea.org.br/etica.htm>. Acesso em: fev. 2003.

CONAB - Companhia Nacional de Abastecimento. Quadro de suprimento, junho de 2006. Disponível em: <http://www.conab. gov.br/download/indicadores/0301-oferta-edemanda-brasileira. pdf $>$. Acesso em: 10 jul. 2006.

CRUZ, G. A. D. R. Avaliação da qualidade e digestibilidade in vivo da proteína de cultivares de feijão (Phaseolus vulgaris $L$.). Viçosa, 2000. 68 p. Dissertação - (Mestrado em Agroquímica), Universidade Federal de Viçosa - UFV.

CRUZ, G. A. D. R. et al. Comparação entre a digetibilidade protéica in vitro e in vivo de diferentes cultivares de feijão (Phaseolus vulgares, L.) armazenados por 30 dias. Alimentos e Nutrição, v. 16, n. 3, p. 265-271, 2005.

DEMJEN, A.; THOMPSON, L. U. Calcium and phytic acid independently lower the glycemic response to a glucose load. In: Proceedings Canadian Fed Biology Society Meeting, Ottawa, 34, 1991. Abstract...Ottawa, 1991, 53 p.
Doles Reagentes e Equipamentos para Laboratórios Ltda. Hemoglobina Glicosilada Doles. Roteiro, outubro/2003. Disponível em: $<$ http:// www.doles.com.br/prods/biocli.html>.

GENOVESE, M. I.; LAJOLO, F. M. Atividade inibitoria de tripsina do feijão (Phaseolus vulgaris L.): Avaliação crítica dos métodos de determinação. Archivos Latinoamericanos de Nutrición, v. 51, n. 4, p. 386-394, 2001.

GILANI, G. S. et al. Effects of dietary protein and fat on cholesterol and fat metabolism in rats. Nutrition Research, v. 22, n. 3, p. 297-311, 2002.

HUANG, Y. S. et al. Interrelationship between dietary protein, cholesterol and n-6 polyunsaturated fatty acid metabolism. Progress in Lipid Research, v. 32, n. 2, p. 123, 1993.

HUGHES, J. S. et al. Effects of dietary fiber and tannins on protein utilization in dry beans (Phaseolus vulgaris). Food Research International, v. 29, n. 3-4, p. 331-338, 1996.

HUGHES, J. S. Potential contribution of dry bean dietary fiber to health. Food Technology, v. 45, n. 9, p. 122-126, 1991.

KERN, M. et al. Effects of soy protein suplemented with methionine on blood lipids and adiposity of rats. Nutrition, v. 18, n. 7-8, p. 654-656, 2002.

LOPEZ, G. et al. Propiedades funcionales de la fibra dietética. Mecanismos de acción en el tracto gastrointestinal. Archivos Latinoamericanos de Nutrición, v. 47, n. 3, p. 203-207, 1997.

MANISHA, C. et al. Beneficial effects of high dietary fiber intake in patients with type 2 diabetes mellitus. The New England Journal of Medicine, v. 342, n. 11, p. 392-1398, 2003.

OLIVEIRA, A. C. et al. Adições crescentes de ácido fítico à dieta não interferem na digestibilidade da caseína e no ganho de peso em ratos. Revista de Nutrição, v. 16, n. 2, p. 211-217, 2003.

PEREIRA, C. A.; COSTA, N. M. Proteínas do feijão preto sem casca: digestibilidade em animais convencionais e isentos de germes (germ-free). Revista de Nutrição, v. 15, n. 1, p. 5-14, 2002.

RAMÍREZ-CÁRDENAS, L.; LEONEL, A.J.; COSTA, N.M.B. Efeito do processamento doméstico sobre o teor de nutrientes e de fatores antinutricionais de diferentes cultivares de feijão comum. Ciência e Tecnologia de Alimentos, Campinas, v. 28, n. 1, p. 200-213, 2008.

RAYAS-DUARTE, P.; BERGERON, D.; NIELSEN, S. S. Screening of heatable trypsin inhibitors in dry beans and their partial purification from Great Northern beans (Phaseolus vulgaris) using anhydrotrypsin-sefharose affinity chromatography. Journal of Agricultural and Food Chemistry, v. 40, n. 1, p. 32-42, 1992.

REEVES, P. G.; NIELSEN, F. H.; FAHEY, C. G. AIN-93. Purified diets for laboratory rodents: Final report of the American Institute of Nutrition Ad Hoc Writing Committee on the reformulation of the AIN-76A rodent diet. Journal of Nutrition, v. 123, n. 11, p. 1939-1951, 1993.

ROSA, C. O. B. et al. Efeito do feijão preto Phaseolus vulgaris, L.) sem casca na redução do colesterol sangüíneo de ratos hipercolesterolêmicos. Archivos Latinoamericanos de Nutrición, v. 48, n. 4, p. 299-305, 1998.

SABARENSE, C. M. et al. Influência das condições de armazenamento na qualidade nutricional das proteínas de feijões (Phaseolus vulgaris L.). Revista Brasileira de Farmácia, v. 76, n. 3, p. 75-78, 1995.

THOMPSON, L. U. Antinutrients and blood glucose. Food Technology, v. 42, n. 4 , p. $123-132,1988$.

. Review Paper: Potential health benefits and problems associated with antinutrients in foods. Food Research International, v. 26, n. 2, p. 131-149, 1993. 
TRINDER, P. Determination of glucose in blood using glucose oxidase with an alternative oxygen aceptor. Annals of Clinical Biochemistry, v. 6, n. 24, p. 24-27, 1969.

WANDER, A. E. Produção e consumo de feijão no Brasil, 1975-2005. Informações Econômicas, v. 37, n. 2, p. 7-21, fev. 2007.

WELCH, R. et al. Genetic selection for enhanced bioavailable levels of iron in bean (Phaseolus vulgaris) seeds. Journal of Agricultural and Food Chemistry, v. 48, n. 25, p. 3576-3580, 2002.

WHO. World Health Organization. 2003. OMS alerta para 'explosão' de diabetes. Disponível em: <http://www.bbc.co.uk/portuguese/ ciencia/story/2003/11/031114_diabetescg.shtml>. Acesso em: nov. 2003.

WOO, K. K. et al.. Effect of resistant starch from corn or rice on glucose control, colonic events, and blood lipid concentrations in streptozotocininduced diabetic rats. Journal of Nutritional Biochemistry, v. 14, n. 3, p. 166-172, 2003.

WU, W. et al. Thermal effects on net protein ratio of red kidney beans (Phaseolus vulgaris). Journal of the Science of Food and Agriculture, v. 71, n. 4, p. 491-495, 1996. 